Plant Tissue Cult. \& Biotech. 26(1): 97-104, 2016 (June)

$\overline{\text { PTC\&B }}$

\title{
Effect of Glutamine, Biotin and ADP on Micropropa- gation and Growth of Chrysanthemum hybridum, Gerbera jamesonii and Cordyline fruticosa In vitro
}

\section{Samarina*, T. Kolomiets, V. Malyarovskaya, S. Gubaz and N. Platonova}

Laboratory of Plant Biotechnology, Physiology and Biochemistry, Russian Research Institute of Floriculture and Subtropical Crops, Jan Fabritsiusa str., 2/28, 354002 Sochi, Russia

Key words: In vitro, Micropropagation, Growth, Microplants

\begin{abstract}
The effect of glutamine, biotin and adenosine diphosphate (ADP) on growth and cultivars micropropagation of three ornamental species was investigated. The addition of $10-100 \mathrm{mg} / \mathrm{l}$ glutamine in culture media significantly increased rate of multiplication in Cordyline fruticosa and $100 \mathrm{mg} / \mathrm{l}$ glutamine showed the same effect for Gerbera jamesonii. Addition of glutamine did not show any effect on shoot length, root number and length in all the three species. Addition of 1 - 3 $\mathrm{mg} / \mathrm{l}$ biotin increased shoot length of Gerbera jamesonii but inhibited shoot length of Cordyline fruticosa and decreased root length of Chrysanthemum hybridum and Gerbera jamesonii. Addition of $5.0 \mathrm{mg} / \mathrm{l}$ ADP significantly increased multiplication rate of Cordyline fruticosa and $1.0 \mathrm{mg} / \mathrm{l}$ ADP showed similar effect for Gerbera jamesonii.
\end{abstract}

\section{Introduction}

The effect of glutamine, biotin and ADP on in vitro propagation of many plant species is not fully investigated. Glutamine is an additional source of organic nitrogen and directly involved in nitrogen assimilation in tissue culture. The addition of glutamine together with $\mathrm{NO}_{3}{ }^{-}$reduced the cytokinin requirement, and enhances cell division without any cytokinin (Meyer and Abel 1975). This amino acid was found effective for some plant species propagated in vitro. Glutamine promoted growth and stimulated somatic embryos production of wild carrot (Anderson 1976) and oil palm (Mariani 2014) cells, enhanced organogenesis in pineapple leaves (Hamasaki et al. 2005), and increased shoot

*Author for correspondence: <q11111w2006@ya.ru>. 
proliferation in Citrus reticulata (Siwach et al. 2012). On the other hand, supplemented medium with $0.5-5.0 \mathrm{mM}$ glutamine greatly decreased organogenesis of Zamia latifolia (Webb and Rivera 1981). There is not much information in literature about effect of glutamine alone on clonal micropropagation and growth of many plant species and this is why further investigation is needed.

Another component of tissue culture media is biotin and little interest has been observed in studying its effect. Some authors say that addition of this water soluble vitamin is important for in vitro organogenesis and growth, others have not found any important role of it for plant in vitro propagation. Addition of this vitamin was found effective for Phoenix dactylifera L. callus initiation and growth: embryogenic callus weight, number of embryos, and embryo length were significantly influenced by biotin (Al-Khayri 2001, EL-Shiaty et al. 2004). It has also been noticed that biotin increased the shoot dry weights of peas (Abrahamian and Kantharajah 2011). On the contrary, omitting vitamins (thiamine, pyridoxine, nicotinic acid, folic acid, and biotin) from a medium did not affect shoot and root formation in 16 cultivars, except one, of Begonia $\times$ Hiemalis (Welander 1977). There is not much information about the effects of biotin on growth and multiplication of microplants in vitro so we aimed at revealing its influences.

ADP is another growth regulator and sufficient information are not available about its application in tissue culture. Some authors noted that addition of either ATP or ADP caused a significant increase in cell division of in vitro synchronized potato (Ipomea batatas L.), cucumber (Cucumis sativus L.) and duckweed (Spirodella polyrhiza L.) cell suspension cultures (Kintzios et al. 2002). Others mentioned that addition of ATP had positive effect on cucumber (Cucumis sativus L.) regeneration from nodal explants (Matakiadis and Kintzios 2005). The authors observed significant increasing number of internodes and length, but also noted a reduction of leaf number as effect of ATP addition. Affects of ADP for the micropropagation of cultivars have not been investigated.

Authors tried to find out the effect of glutamine, biotin and ADP for micropropagation of commercially important ornamental species Chrysanthemum hybridum Guss., Gerbera jamesonii Bolus ex Hooker f. and Cordyline fruticosa (L.) A. Chev.

\section{Materials and Methods}

Cultivars of three species, namely Chrysanthemum hybridum Guss. cv. Yoder white, Gerbera jamesonii Bolus ex Hooker f. cv. Harriet and Cordyline fruticosa (L.) A. Chev. cv. Kiwi were used for in vitro micropropagation. Clones of these three 
genotypes were micropropagated on half strength of MS supplemented with 0.05 $\%$ casein hydrolysate, $2.5 \%$ sucrose and $0.25 \%$ phytagel. $\mathrm{pH}$ was adjusted to 5.75 - 5.85 before autoclaving at $120^{\circ} \mathrm{C}$ for $25 \mathrm{~min}$. Four to five explants were placed in each jar and incubated in light chamber under fluorescent tubes with photoperiod $16 / 8 \mathrm{hrs}$ and light intensity $2000 \mathrm{lk}$ at $24 \pm 2^{\circ} \mathrm{C}$.

Glutamine, biotin and ADP were added in the above mentioned medium before autoclaving. Treatments are represented in Table 1.

Table 1. Concentrations of plant growth regulators (PGR) in culture media.

\begin{tabular}{llllll}
\hline PGR & \multicolumn{5}{c}{ Treatments } \\
\cline { 2 - 6 }$(\mathrm{mg} / \mathrm{l})$ & Control & 1 & 2 & 3 & 4 \\
\hline Glutamin & 0 & 10 & 50 & 100 & - \\
Biotin & 0 & 1 & 3 & 6 & 9 \\
ADP & 0.0 & 0.5 & 1.0 & 2.0 & 5.0 \\
\hline
\end{tabular}

Growth parameters of microplants were evaluated after one month of propagation on experimental media. Multiplication rate (the number of explants which can be derived from one microplant after one month) was recorded as well as number and length of roots and length of microplants.

Each treatment included 8 - 10 replicates and experiment was repeated twice. Results were assessed by a standard analysis of variance for a completely randomized design, using MS-STATISTICA software.

\section{Results and Discussion}

It was observed that glutamine affected significantly on multiplication rate of two species (Fig. 1). Multiplication rates of Cordyline fruticosa cv. Kiwi and Gerbera jamesonii cv. Harriet were two times higher when 10 - 100 and $100 \mathrm{mg} / \mathrm{l}$ of glutamine was added. Gerbera jamesonii cv. Harriet did not show any change when 10 and $50 \mathrm{mg} / \mathrm{l}$ glutamine was added in the medium as shown in Fig. 1. There were also no significant differences of multiplication rate in Chrysanthemum hybridum cv. Yoder white.

In the three plant species there were no significant differences between treatments in shoot length, root number and root length when glutamine was added in plant culture medium (data are not shown). Our results on addition of glutamine showed only specific plant reaction of gerbera and cordyline cultivars.

Addition of glutamine showed no effect on height of microplants and rooting parameters. 
It was previously shown that addition of amino acids has a positive effect on plant growth as a source of organic nitrogen (Thorpe et al. 2008). Addition of glutamine to the culture medium enhanced organogenesis and micropropagation of some species. The organogenesis competence of pineapple cells increased to $70 \%$ when the medium was supplemented with $1.2 \mathrm{~g} / 1$ glutamine was supplemented to culture media (Hamasak et al. 2005). Addition of $1.5 \mathrm{~g} / \mathrm{l}$ glutamine significantly increased somatic embryo germination in oil palm (Mariani 2014). But there is no information about glutamine effect on clonal micropropagation and growth. Repeatedly noted a positive effect of glutamine in combination with other growth regulators on micropropagation (EL-Shiaty et al. 2004, Siwach et al. 2012, Medza Mve et al. 2013), but in this case it is difficult to establish specific effect of each amino acid. The aim of our research was to reveal the action of glutamine alone in micropropagation of three commercially important ornamental crops. Our data showed that glutamine in culture media increased multiplication rate in gerbera and cordyline, but has no effect on chrysanthemum multiplication and no other effects on growth and root parameters.

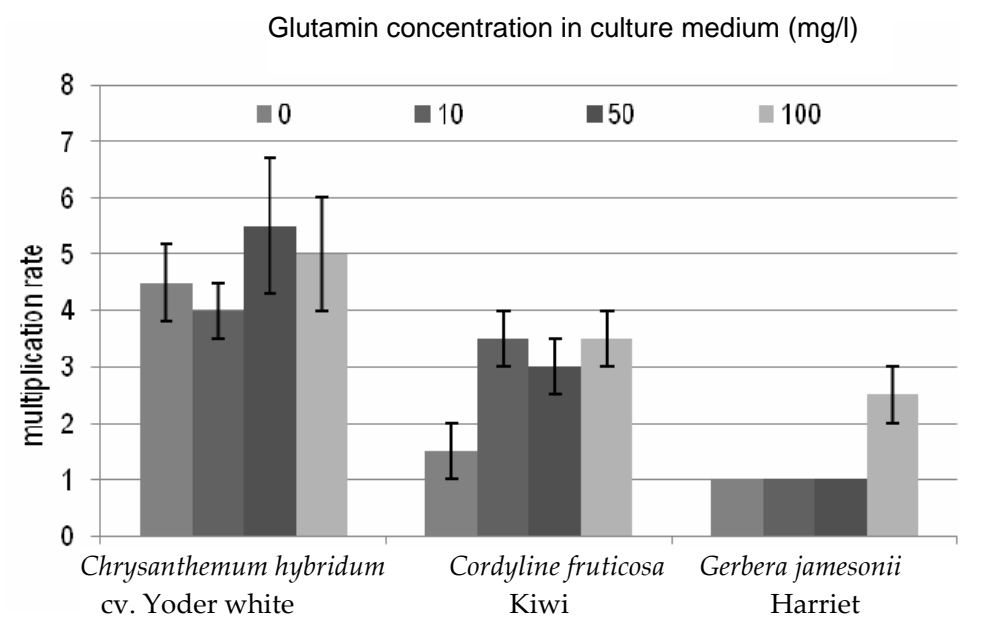

Fig. 1. Effect of glutamine in culture medium on multiplication rate of Chrysanthemum hybridum, Gerbera jamesonii and Cordyline fruticosa.

Evaluation of morphological changes under biotin influence showed the effect of this vitamin on shoot and root length. It was noted that biotin increased shoot length in Gerbera jamesonii cv. Harriet and the best results were obtained 
when 1 - $3 \mathrm{mg} / \mathrm{l}$ biotin was added to the medium, average shoot length was 5.4 $6.3 \mathrm{~cm}$ (Fig. 2).

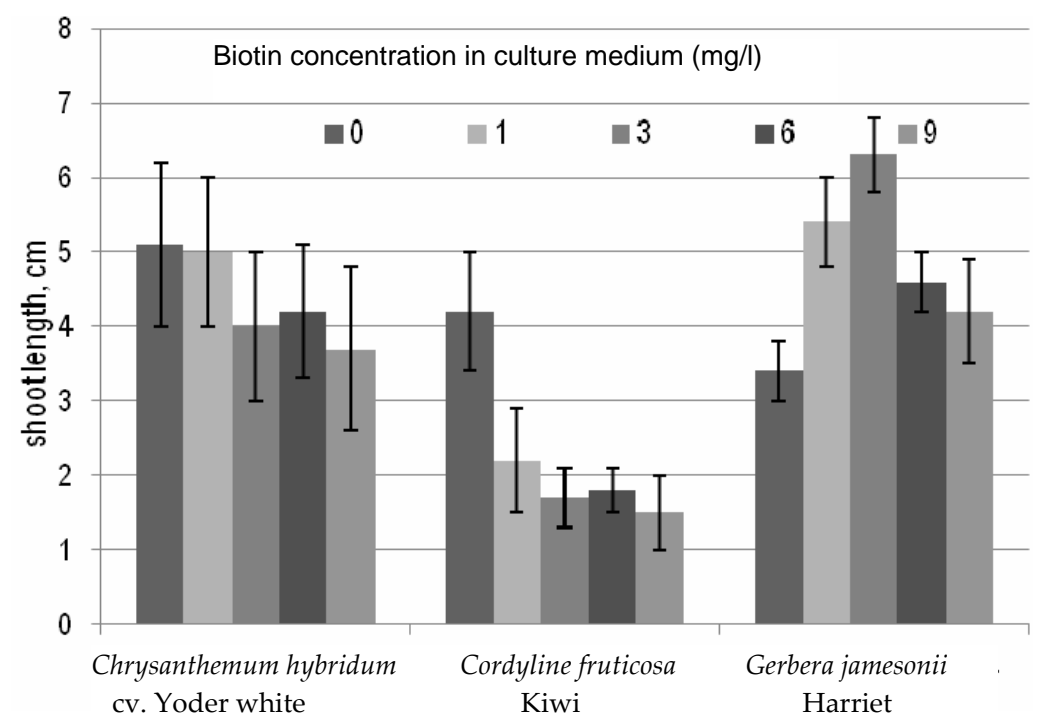

Fig. 2. Effect of biotin in culture medium on shoot length of Chrysanthemum hybridum cv. Yoder white, Gerbera jamesonii cv. Harriet and Cordyline fruticosa cv. Kiwi.

Cordyline fruticosa microplants showed two times decreasing of shoot length compared to control when $1-9 \mathrm{mg} / \mathrm{l}$ biotin was added. It is also interesting to note that there was no significant difference in shoot length between treatments with 1 - $9 \mathrm{mg} / \mathrm{l}$.

In case of Chrysanthemum hybridum cv. Yoder white, addition of biotin has no significant effect in shoot length of microplants.

It was revealed that addition of biotin in culture media caused decreasing of root length of Chrysanthemum hybridum cv. Yoder white and Cordyline fruticosa cv. Kiwi microplants (Fig. 3). There were no significant differences in Gerbera jamesonii $\mathrm{cv}$. Harriet rooting in presence of biotin as well as no other significant effects on the number of roots and multiplication rate in these three species (data are not shown).

Results demonstrated specific effect of biotin on shoot length of cordyline and gerbera microplants. Furthermore, root length decreasing was revealed in cordyline and chrysanthemum microplants as effect of biotin presence. Biotin is known to have a catalytic role as an enzyme cofactor, and this vitamin also has multiple roles in regulating gene expression in plants (Che et al. 2003). Concerning regulatory action of biotin, some authors reported its enhancing 
effect on callus growth and somatic embryogenesis in a concentration of 1 - 2 $\mathrm{mg} / \mathrm{l}$ (Al-Khayri et al. 2001, EL-Shiaty et al. 2004). Our results showed its controversial effect on plant growth that is why further investigations of biotin action with a number of replicates is needed.

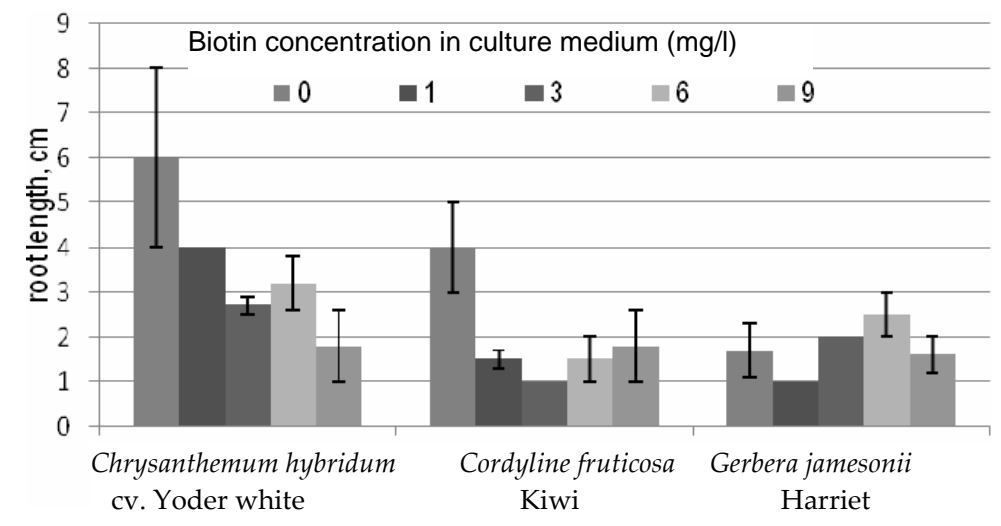

Fig. 3. Effect of biotin on root length of Chrysanthemum hybridum cv. Yoder white, Gerbera jamesonii cv. Harriet and Cordyline fruticosa cv. Kiwi.

Addition of ADP did not influence the shoot length, root number and root length of microplants. However, significant differences were observed in multiplication rate of microplants (Fig. 4). Addition of 2 - $5 \mathrm{mg} / \mathrm{l} \mathrm{ADP}$ two times enhanced multiplication rate of Cordyline fruticosa cv. Kiwi microplants.

Microplants of Gerbera jamesonii cv. Harriet showed the highest multiplication rate when $1 \mathrm{mg} / \mathrm{l}$ ADP was added. In this case we obtained 3.5 shoots per microplant compared to control where no multiplication was observed.

It should be noted that microplants of Chrysanthemum hybridum cv. Yoder white were no dependent on $0.5-5.0 \mathrm{mg} / \mathrm{l} \mathrm{ADP}$ and there was no significant differences in their multiplication rate compared to control.

Regulatory role of ADP was previously not reported enough for plant tissue culture, but there was repeatedly demonstrated that purine nucleotides enhance the growth and division of a large variety of mammalian cells (Schulze-Lohoff et al. 1995, Cheng and Li 1997). The authors studied an action of extracellular ATP into the medium, and they suggested mitogenic effect is unlikely induced by ATP entering cells, but may be mediated by purinergic receptors which activate signaling pathways (Cheng et al. 1997). However, there are limited number of reports on growth regulating effects of purine nucleotides especially ADP on plant cells (Kintzios et al. 2002, Demidchik et al. 2003, Matakiadis et al. 
2005). In our experiments ADP showed significant cytokinin activity in gerbera and cordyline species and possibly has a potential as cost-effective plant growth regulator for micropropagation. ADP regulatory action on micropropagation and growth needs to be further investigated using other plant species and different concentrations in culture media.

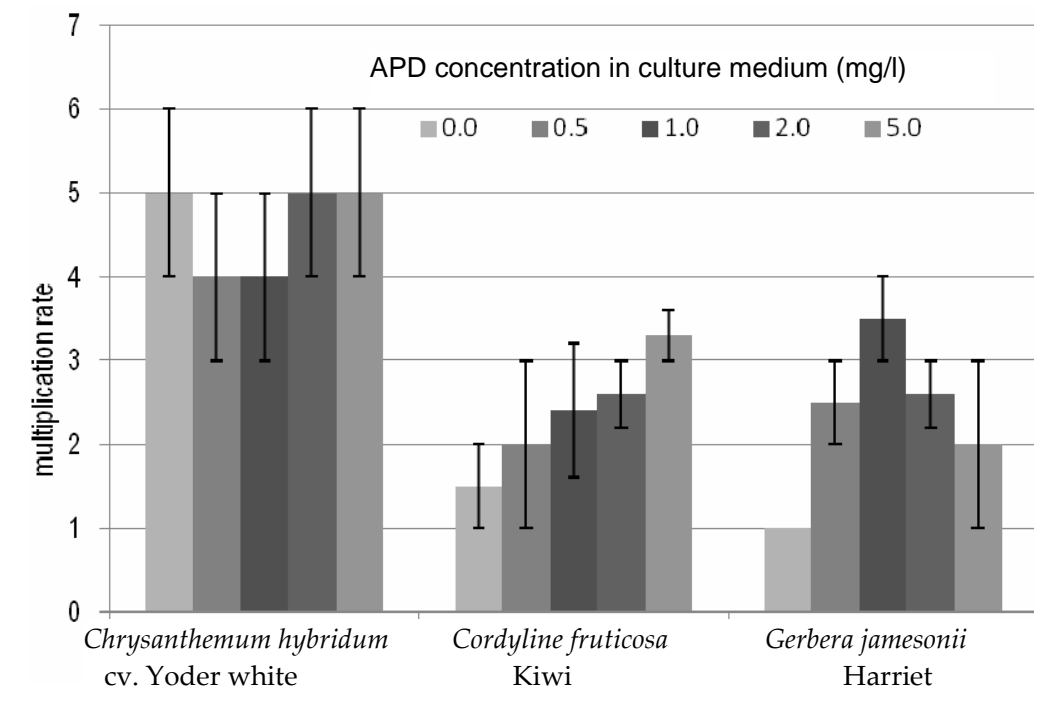

Fig. 4. Effect of ADP on multiplication rate of Chrysanthemum hybridum cv. Yoder white,

Gerbera jamesonii cv. Harriet and Cordyline fruticosa cv. Kiwi.

In conclusion our research demonstrated the specific effects of three plant growth regulators on micropropagation of three commercially important ornamental species. Glutamine and ADP were efficient for increasing multiplication rate of gerbera and cordyline microplants. Biotin affected shoot and root length in three studied species. For the first time the authors demonstrated the effect of ADP on micropropagation of gerbera and cordyline cultivars. These results confirmed the importance of addition of glutamine, biotin and ADP as growth regulators for micropropagation and showed the necessity of tissue culture protocols development according to certain plant genotypes.

\section{References}

Abrahamian P and Kantharajah A (2011) Effect of vitamins on in vitro organogenesis of plant. Amer. J. Plant Sci. 2(5): 669-674.

Al-Khayri JM (2001) Optimization of biotin and thiamine requirements for somatic embryogenesis of date palm (Phoenix dactylifera L.). In vitro Cellular \& Developmental Biology - Plant 37(4): 453-456. 
Che P, Weaver LM, Wurtele ES and Nikolau BJ (2003) The role of biotin in regulating 3methylcrotonylcoenzyme a carboxylase expression in Arabidopsis. Plant Physiology 131: $1479-1486$.

Cheng X and Li X (1997) Exogeneous adenosine triphosphate promotes proliferation of renal tubular epithelial cells. Chung Hua I Hsueh Tsa Chih. 77: 351-354.

EL-Shiaty OH, El-Sharabasy SF and El-Kareim AH (2004) Effect of some amino acids and biotin on callus and proliferation of date palm (Phoenix dactylifera L.) Sewy cultiver Arab J. Biotech. 7(2): 265-272.

Hamasaki RM, Purgatto E and Mercier H (2005) Glutamine enhances competence for organogenesis in pineapple leaves cultivated in vitro. Braz. J. Plant Physiol. 17(4): 383-389.

Meyer Y and Abel WO (1975) Budding and cleavage division of tobacco mesophyll protoplasts in relation to pseudo-wall and wall formation. Planta 125: 1-13.

Mariani TS, Purnaning AS and Latif DS (2014) Effect of glutamine addition in maturation stage on the germination and plantlet conversion of oil palm (Elaeis guineensis Jacq.) Somatic Embryo. Asian J. Appl. Sci. 2(5): 663-667.

Matakiadis T and Kintzios S (2005) The effect of ATP on cucumber (Cucumis sativus L.) regeneration from nodal explants: association with a-tocopherol, $\mathrm{H}_{2} \mathrm{O}_{2}$ and size of culture vessel. Plant Growth Regulation 45: 127-137.

Medza Mve SD, Mergeai G, Druart P, Pierre BJ and Toussaint A (2013) In vitro Micropropagation of Jatropha curcas L. from bud aggregates. J. Technol. Innovations in Renewable Energy 2: 145-154.

Schulze-Lohoff E, Schagerl S, Ogilvie A and Sterzel RB (1995) Extracellular ATP augments mesangial cell growth induced by multiple growth factors. Nephrol. Dial Transplant 10: 2027-2034.

ch P, Chanana S, Rani Gill A, Dhanda P, Rani J, Sharma K, Rani H and Kumari D (2012) Effects of adenine sulphate, glutamine and casein hydrolysate on in vitro shoot multiplication and rooting of Kinnow mandarin (Citrus reticulata Blanco). African J. Biotechnol. 11(92): 15852-15862.

Thorpe T, Stasolla C, Yeung EC, de Klerk G-J, Roberts A and George EF (2008) The components of plant tissue culture media II : Organic additions, osmotic and $\mathrm{pH}$ effects, and support systems. Plant Propagation by Tissue Culture 3rd edit. Springer, Netherlands, p. 504 .

Welander T (1977) In vitro organogenesis in explants from different cultivars of Begonia $\mathrm{x}$ Hiemalis. Physiologia Plantarum. 41(2): 142-145. 